\title{
Thyroid Function and High-Sensitivity C-Reactive Protein in Cross-Sectional Results from the Brazilian Longitudinal Study of Adult Health (ELSA-Brasil): Effect of Adiposity and Insulin Resistance
}

\author{
Érique José F. Peixoto de Miranda Márcio Sommer Bittencourt \\ Itamar S. Santos Paulo A. Lotufo Isabela M. Benseñor \\ Centro de Pesquisa Clínica, Hospital Universitário, Universidade de São Paulo, São Paulo, Brazil
}

\section{Key Words \\ Cardiovascular risk factors · C-reactive protein · Insulin resistance - Obesity - Subclinical hypothyroidism - Systemic inflammation - Thyroid dysfunction}

\begin{abstract}
Background: Subclinical hypothyroidism ( $\mathrm{SCH}$ ) is associated with an increased cardiovascular risk, but little information is available about its association with high-sensitivity C-reactive protein (hs-CRP). Objectives: This study aims to analyze the association between SCH and hs-CRP using baseline data from the Brazilian Longitudinal Study of Adult Health (ELSABrasil). Methods: The study has a cross-sectional design. We included subjects with normal thyroid function (thyroidstimulating hormone, TSH, $0.4-4.0 \mu \mathrm{U} / \mathrm{ml}$ and normal free thyroxine, $\left.\mathrm{fT}_{4}, 10.3-24.45 \mathrm{pmol} / \mathrm{l}\right)$ and $\mathrm{SCH}(\mathrm{TSH}>4.0 \mu \mathrm{lU} / \mathrm{ml}$ and normal $\mathrm{fT}_{4}$ ) who were evaluated for hs-CRP. We excluded individuals on medications that affect thyroid function and those who had prevalent cardiovascular disease. Multivariate linear regression evaluated hs-CRP and TSH as continuous variables, and logistic regression models assessed hs-CRP $\geq 19.05 \mathrm{nmol} / \mathrm{l}$ as the dependent variable and crescent quintiles of TSH as the independent variables adjusted
\end{abstract}

for demographic and cardiovascular risk factors. Results: We included 12,284 subjects with a median age of 50 years (interquartile range $=45-57) ; 6,408(52.2 \%)$ were female, 11,589 (94.3\%) were euthyroid, and 695 (5.7\%) had SCH. Bivariate analyses of participants stratified into quintiles of TSH revealed differences according to hs-CRP but not the Framingham risk score. The fifth quintile of TSH was not associated with elevated hs-CRP, odds ratio $=1.11$ (95\% confidence interval $=0.98-1.26), p=0.102$, in a fully adjusted logistic model, also consistent with the linear model ( $\beta=0.024, p=0.145)$. Conclusions: TSH is not associated with hs-CRP. Obesity and insulin resistance are very important confounders in the study of the association between SCH and hs-CRP.

(C) 2016 European Thyroid Association Published by S. Karger AG, Basel

\section{Introduction}

The link between subclinical hypothyroidism (SCH), which is defined as high serum thyroid-stimulating hormone (TSH) concomitant with normal serum free thyroxine levels $\left(\mathrm{fT}_{4}\right)$ [1], and cardiovascular disease remains controversial. Some prospective cohort studies have

\section{KARGER}

E-Mail karger@karger.com www.karger.com/etj
(C) 2016 European Thyroid Association

Published by S. Karger AG, Basel

$2235-0640 / 16 / 0054-0240 \$ 39.50 / 0$ 
found an association $[2,3]$, while others have not $[4,5]$. One large meta-analysis showed an association between $\mathrm{SCH}$ and an increased risk of coronary heart disease and cardiovascular mortality only in individuals with TSH values exceeding $7.0 \mathrm{mIU} / \mathrm{l}$, and particularly above 10 $\mathrm{mIU} / \mathrm{l}[6]$.

In spite of this controversy, some studies have linked SCH with hypertension [7], obesity [8], dyslipidemia [9], metabolic syndrome [10], insulin resistance [10], and subclinical atherosclerosis, especially aortic atherosclerosis [11], and carotid intima-media thickness [12] but not in a consistent manner.

High-sensitivity C-reactive protein (hs-CRP) is an acute-phase protein synthesized by the liver in response to infection and chronic inflammatory diseases [13]. Beyond that, hs-CRP is a predictor of future cardiovascular events and probably participates directly in the pathogenesis of atherosclerosis through activation of endothelial cells and coronary artery smooth muscle cells [13].

Large observational studies have established a relationship between hs-CRP, across a full range of values, and the morbidity and mortality associated with coronary heart disease $[14,15]$, and have improved the prediction of cardiovascular risk by adding hs-CRP to the Framingham risk score [16]. Other studies have found an association between hs-CRP and measures of subclinical atherosclerosis, such as coronary artery calcification and intima-media thickness [17]. The mechanism underlying this association is still unknown, but some clinical trials have shown an association between decreasing levels of atherogenic lipoproteins by statin therapy and concomitant decreases in systemic inflammation [18]. CRP also decreases as a result of interventions such as exercise, weight loss, smoking cessation, and the use of fibrates in a dose-response relationship [19].

The association between SCH and hs-CRP is still controversial [20,21]; therefore, we aimed to cross-sectionally examine the association between $\mathrm{SCH}$ and hs-CRP as a surrogate marker for systemic inflammation using baseline data from the Brazilian Longitudinal Study of Adult Health (ELSA-Brasil), an ongoing prospective cohort study in Brazil with information about thyroid function and hs-CRP levels.

\section{Methods}

\section{Study Population}

This study is a cross-sectional analysis of the baseline data from the ELSA-Brasil study.

Thyroid Function and CRP
The ELSA-Brasil protocol has been published elsewhere [22]. Briefly, this study included 15,105 civil employees (aged 35-74 years) in six centers, and its main objective is to determine the incidence of cardiovascular diseases and diabetes and their associated risk factors $[22,23]$. The ELSA-Brasil protocol was approved at all six centers by the respective Institutional Review Boards addressing research in human participants according to the Declaration of Helsinki. Written informed consent was obtained from all participants.

The baseline data for the ELSA-Brasil study were collected between August 2008 and December 2010. Each participant was interviewed in their workplace and each visited one of the Research Centers for clinical examinations according to standard protocols. At all sites, the interviews and examinations were conducted by trained personal with strict quality control [24]. Questionnaires addressed age, gender, self-reported race (white, mixed, black, Asian, and indigenous), and smoking status (never, former, and current). All medications taken during the 15 days prior were carefully reviewed.

\section{Definition of Thyroid Function}

$\mathrm{TSH}$ and $\mathrm{fT}_{4}$ were measured using a third-generation immunoenzymatic assay (Siemens, Deerfield, Ill., USA) in serum obtained from centrifuged samples of venous blood taken after an overnight fast. $\mathrm{fT}_{4}$ levels were only evaluated in participants who presented altered TSH levels. In this study, reference range levels were $0.4-4.0 \mu \mathrm{IU} / \mathrm{ml}$ for TSH and $10.3-24.45 \mathrm{pmol} / \mathrm{l}$ for $\mathrm{fT}_{4}$, i.e. similar to those used in the National Health and Nutritional Examination Survey (NHANES III) [25] and recommended by Surks et al. [26].

Participants in the ELSA-Brasil study were classified into five categories of thyroid function, according to $\mathrm{TSH}$ and $\mathrm{fT}_{4}$ levels (if TSH was altered) and information regarding the use of medication to treat thyroid disorders: clinical hyperthyroidism (low serum $\mathrm{TSH}$ and high levels of $\mathrm{fT}_{4}$ or use of medication to treat hyperthyroidism), subclinical hyperthyroidism (low serum TSH, normal levels of $\mathrm{fT}_{4}$, and no use of thyroid drugs), euthyroidism (normal TSH and no use of thyroid drugs), SCH (high TSH levels, normal levels of $\mathrm{fT}_{4}$, and no use of thyroid drugs), and clinical hypothyroidism (high $\mathrm{TSH}$ and low $\mathrm{fT}_{4}$ levels or use of levothyroxine to treat hypothyroidism. In this study, we analyzed only participants who were euthyroid or had SCH.

We also excluded participants using drugs that can interfere with thyroid function, such as amiodarone, biotin, carbamazepine, carbidopa, phenytoin, furosemide, haloperidol, heparin, interferon, levodopa, lithium, metoclopramide, propranolol, primidone, rifampicin, and valproic acid $[27,28]$, and participants with a prior history of cardiovascular disease.

\section{C-Reactive Protein}

hs-CRP levels were measured using immunochemistry (nephelometry; Siemens). Values were log transformed for comparison, but the values in the tables have been back transformed to their natural scales. The variable hs-CRP was categorized as $<19.05$ or $\geq 19.05 \mathrm{nmol} / \mathrm{l}(2.0 \mathrm{mg} / \mathrm{l})$, a cutoff which has been strongly supported by studies $[14,15,18]$.

\section{Cardiovascular Risk Factors}

Blood pressure (BP) was taken three times using the validated Omron HEM 705CPINT oscillometric device. The mean of the 
Table 1. General characteristics of the sample according to the quintiles of TSH in euthyroid and SCH participants

\begin{tabular}{|c|c|c|c|c|c|c|}
\hline & \multicolumn{5}{|l|}{ Quintile of TSH } & $\mathrm{p}$ value \\
\hline Age, years & $50(44-57)$ & $50(44-57)$ & $50(44-57)$ & $50(45-57)$ & $52(45-59)$ & $<0.0001$ \\
\hline Women & $1,287(51.9)$ & $1,212(50.4)$ & $1,292(52.1)$ & $1,280(52.1)$ & $1,337(54.3)$ & 0.110 \\
\hline Race & & & & & & $<0.0001$ \\
\hline Black & $752(30.7)$ & $751(31.6)$ & $694(28.3)$ & $642(26.4)$ & $636(26.2)$ & \\
\hline Asian & $51(2.1)$ & $59(2.5)$ & $78(3.2)$ & $58(2.4)$ & $56(2.3)$ & \\
\hline Indigenous & $26(1.1)$ & $27(1.1)$ & $23(0.9)$ & $24(1.0)$ & $23(0.9)$ & \\
\hline Mean BMI (SD) & $26.6(4.5)$ & $26.7(4.5)$ & $26.8(4.8)$ & $26.9(4.7)$ & $27.1(4.9)$ & 0.002 \\
\hline Hypertension & $795(32.1)$ & $781(32.5)$ & $800(32.3)$ & $757(30.9)$ & $784(31.9)$ & 0.774 \\
\hline Diabetes mellitus & $472(19.0)$ & $454(18.9)$ & $429(17.3)$ & $413(16.8)$ & $412(16.7)$ & 0.076 \\
\hline Never & $1,333(53.8)$ & $1,375(57.2)$ & $1,468(59.2)$ & $1,457(59.3)$ & $1,475(59.9)$ & \\
\hline Past & $706(28.5)$ & $668(28.6)$ & $672(27.1)$ & $716(29.1)$ & $769(31.2)$ & \\
\hline Current & $441(17.8)$ & $342(14.2)$ & $338(13.6)$ & $284(11.6)$ & $219(8.9)$ & \\
\hline Obesity & $497(20.1)$ & $505(21.0)$ & $535(21.6)$ & $561(22.8)$ & $558(22.7)$ & 0.101 \\
\hline Metabolic syndrome & $772(31.1)$ & $796(33.1)$ & $777(31.3)$ & $796(32.4)$ & $839(34.1)$ & 0.150 \\
\hline CKD & $97(3.9)$ & $125(5.2)$ & $125(5.0)$ & $154(6.3)$ & $178(7.2)$ & $<0.0001$ \\
\hline 10-year CHD risk & $6.0(3.0-9.0)$ & $6.0(3.0-9.0)$ & $5.0(3.0-9.0)$ & $5.0(3.0-9.0)$ & $6.0(3.0-9.0)$ & 0.277 \\
\hline $\mathrm{CRP}, \mathrm{nmol} / \mathrm{l}$ & $13.2(6.57-29.2)$ & $13.1(6.48-30.9)$ & $13.4(6.76-30.3)$ & $13.6(6.67-30.9)$ & $14.0(7.14-31.2)$ & 0.268 \\
\hline$\geq 19.05 \mathrm{nmol} / \mathrm{l}$ & $916(36.9)$ & $928(38.6)$ & $947(38.2)$ & $984(40.0)$ & $979(39.7)$ & 0.161 \\
\hline
\end{tabular}

Means (SD), medians (IQR) and $\mathrm{n}(\%)$ are shown. $\mathrm{CHD}=$ Coronary heart disease risk by Framingham risk score. Hypertriglyceridemia was defined as triglyceride levels $>1.69 \mathrm{mmol} / \mathrm{l}$. Insulin resistance was defined as HOMA-IR $\geq 75$ th percentile. ${ }^{\mathrm{a}} \mathrm{HDL}$ cholesterol $<1.03 \mathrm{mmol} / \mathrm{l}$ in men and $<1.29 \mathrm{mmol} / \mathrm{l}$ in women.

two latter BP measurements was considered the value for defining hypertension. Hypertension was defined as the use of medication to treat hypertension, or systolic BP $\geq 140 \mathrm{~mm} \mathrm{Hg}$ or diastolic BP $\geq 90 \mathrm{~mm} \mathrm{Hg}$. Body mass index (BMI) was calculated by dividing weight in kilograms by height in square meters. Obesity was defined as a BMI $\geq 30$. Dyslipidemia was defined as an LDL cholesterol level $\geq 3.37 \mathrm{mmol} / \mathrm{l}$ or use of lowering cholesterol medications, and hypertriglyceridemia as serum triglyceride level $\geq 1.69$ $\mathrm{mmol} / \mathrm{l}$. Diabetes was defined as previous medical history of diabetes, use of medication to treat diabetes, fasting plasma glucose $\geq 6.99 \mathrm{mmol} / \mathrm{l}$, 2-hour plasma glucose $\geq 11.1 \mathrm{mmol} / \mathrm{l}$, or $\mathrm{HbA}_{1 \mathrm{C}}$ $\geq 6.5 \%$. Chronic kidney disease (CKD) was defined as a glomerular filtration rate $<60 \mathrm{ml} / \mathrm{min} / 1.73 \mathrm{~m}^{2}$ according to CKD-EPI $[29,30]$.

Insulin resistance was estimated using the homeostasis model assessment for insulin resistance (HOMA-IR) based on the following formula: fasting glucose $(\mathrm{mg} / \mathrm{dl}) \times$ insulin $(\mu \mathrm{IU} / \mathrm{ml}) / 405$. HOMA-IR values above the 75 th percentile were considered elevated. The metabolic syndrome was defined according to the National Cholesterol Education Program - Adult Treatment Panel III criteria as the presence of three of the following items: waist measurement $\geq 88 \mathrm{~cm}$ for women or $\geq 102 \mathrm{~cm}$ for men, HDL-cholesterol $<1.29 \mathrm{mmol} / \mathrm{l}$ for women or $<1.03 \mathrm{mmol} / \mathrm{l}$ for men, systolic $\mathrm{BP} \geq 130 \mathrm{~mm} \mathrm{Hg}$ or diastolic $\mathrm{BP} \geq 85 \mathrm{~mm} \mathrm{Hg}$, serum triglyceride $\geq 1.69 \mathrm{mmol} / \mathrm{l}$, and fasting plasma glucose $\geq 6.11 \mathrm{mmol} / 1$ [31]. The
Framingham risk score for estimating the absolute 10-year cardiovascular risk (in \%) was calculated according to criteria described elsewhere [31]. Briefly, it is a simplified coronary prediction model, building on age in years, gender, total cholesterol, HDL cholesterol, smoking, systolic BP, and use of medication to treat hypertension using data from the Framingham Heart Study after a 12year follow-up. [32].

\section{Laboratory Tests}

To measure fasting and post-load glucose levels, we used the hexokinase method (ADVIA 1200; Siemens): for fasting and postload insulin, the immunoenzymatic assay; for glycated hemoglobin, high-performance liquid chromatography (Bio-Rad Laboratories, Hercules, Calif., USA), and for total and HDL cholesterol and triglycerides, the enzymatic colorimetric assay (ADVIA 1200). LDL cholesterol was calculated using the Friedewald equation, except in participants with elevated triglyceride levels $(>4.52 \mathrm{mmol} / \mathrm{l})$, in whom the enzymatic colorimetric assay was used (ADVIA 1200).

\section{Statistical Analysis}

Continuous variables were expressed as means (SD) or medians (interquartile ranges, IQR), and compared using analysis of variance (ANOVA), the Mann-Whitney U test, or the Kruskal- 
Table 2. OR and 95\% CI of associations of increased hs-CRP ( $\geq 19.05 \mathrm{nmol} / \mathrm{l})$ according to quintiles of TSH levels in subjects with SCH and euthyroidism

\begin{tabular}{llccr}
\hline & Quintiles of TSH & & & \\
\cline { 2 - 5 } & crude & model 1 & model 2 & model 3 \\
\hline SCH and euthyroid $(n=12,284)$ & & & & \\
1st $(0.41-0.98 \mu \mathrm{IU} / \mathrm{ml})$ & 1.0 (reference) & 1.0 (reference) & 1.0 (reference) & $1.0($ reference) \\
2nd $(0.99-1.34 \mu \mathrm{IU} / \mathrm{ml})$ & $1.07(0.96-1.20)$ & $1.10(0.97-1.23)$ & $1.09(0.96-1.23)$ & $1.08(0.95-1.22)$ \\
3rd $(1.35-1.79 \mu \mathrm{IU} / \mathrm{ml})$ & $1.06(0.94-1.18)$ & $1.10(0.98-1.23)$ & $1.11(0.98-1.25)$ & $1.06(0.93-1.20)$ \\
4th $(1.80-2.58 \mu \mathrm{IU} / \mathrm{ml})$ & $1.14(1.02-1.28)$ & $1.19(1.06-1.34)$ & $1.21(1.07-1.36)$ & $1.14(1.01-1.29)$ \\
5th $(2.59-141 \mu \mathrm{IU} / \mathrm{ml})$ & $1.13(1.01-1.26)$ & $1.17(1.04-1.32)$ & $1.20(1.07-1.36)$ & $1.11(0.98-1.26)$ \\
\hline Euthyroid $(n=11,589)$ & & & & \\
1st $(0.41-0.96 \mu \mathrm{IU} / \mathrm{ml})$ & $1.0($ reference) & $1.0($ reference) & $1.0($ reference $)$ & $1.0($ reference) \\
2nd $(0.96-1.30 \mu \mathrm{IU} / \mathrm{ml})$ & $1.07(0.96-1.20)$ & $1.10(0.98-1.23)$ & $1.09(0.96-1.23)$ & $1.08(0.95-1.22)$ \\
3rd $(1.31-1.70 \mu \mathrm{IU} / \mathrm{ml})$ & $1.06(0.94-1.18)$ & $1.10(0.98-1.24)$ & $1.11(0.98-1.25)$ & $1.06(0.93-1.20)$ \\
4th $(1.71-2.35 \mu \mathrm{IU} / \mathrm{ml})$ & $1.14(1.02-1.28)$ & $1.19(1.06-1.34)$ & $1.21(1.07-1.36)$ & $1.14(1.01-1.29)$ \\
5th $(2.36-4.00 \mu \mathrm{IU} / \mathrm{ml})$ & $1.11(0.98-1.25)$ & $1.15(1.01-1.31)$ & $1.18(1.03-1.34)$ & $1.10(0.95-1.26)$ \\
\hline
\end{tabular}

Model 1 - adjusted for age, sex, race, and skin/color; model 2 - model 1 plus hypertension, diabetes, dyslipidemia, smoking, low HDL cholesterol, hypertriglyceridemia, and CKD; model 3 - model 2, plus BMI (continuous) and insulin resistance.

Table 3. $\beta$ coefficients and $95 \%$ CI of multivariate linear models that evaluated $\ln ($ hs-CRP) as outcome and $\ln (\mathrm{TSH})(\mathrm{mIU} / \mathrm{l})$ as dependent variable

\begin{tabular}{lllll}
\hline & \multicolumn{2}{l}{$\mathrm{SCH}$ and euthyroid subjects $(\mathrm{n}=12,284)$} & model 3 \\
\cline { 2 - 5 } & crude & model 1 & model 2 & $0.024(-0.008-0.055)$ \\
\hline $\ln (\mathrm{TSH})$ & $0.047(0.012-0.081)$ & $0.057(0.022-0.092)$ & $0.057(0.024-0.091)$ & 0.145 \\
\hline
\end{tabular}

Model 1 - adjusted for age, sex and race; model 2 - model 1 plus hypertension, diabetes, dyslipidemia, smoking, low HDL cholesterol, hypertriglyceridemia, and CKD; model 3 - model 2, plus BMI (continuous) and insulin resistance.

Wallis test, as deemed appropriate after assessing normality assumptions. Categorical variables were expressed as proportions and compared using the $\chi^{2}$ or Fisher's exact test, as appropriate. HOMA-IR and hs-CRP were log transformed for comparison, but the values in the tables have been back transformed to their natural scales. TSH was divided by ascending quintiles: from first (lower values) to fifth (upper values). The first quintile was defined as the reference category.

Logistic regression models were built using hs-CRP categorized as $<19.05$ or $\geq 19.05 \mathrm{nmol} / \mathrm{l}$ as the dependent variable, and quintiles of TSH or SCH as the independent variable. Odds ratios (OR) and 95\% confidence intervals (95\% CI) are presented as crude and adjusted for sociodemographic characteristics, such as age, sex, and race/skin color in model 1. Model 2 includes all the variables in model 1 plus cardiovascular risk factors such as hypertension, diabetes, dyslipidemia, smoking, low HDL cholesterol level, hypertriglyceridemia, and CKD (measured by CKD-EPI). Mod- el 3 includes all the variables in model 2 plus BMI and insulin resistance. Linear regression models used the same adjustment of logistic models.

The analyses were done using SPSS 20.0 software (IBM, Chicago, Ill., USA). p $<0.05$ was regarded as significant, and all tests were two sided.

\section{Results}

A sample of 14,988 subjects retrieved from the 15,105 participants in the ELSA-Brasil study was evaluated for hs-CRP. After applying exclusion criteria, we included 12,284 subjects with a median age of 50 years (IQR $=45-$ $57)$; 6,408 (52.2\%) were females, 11,589 (94.3\%) were eu- 
thyroid, and 695 (5.7\%) had SCH. Details on the study design can be found in the flowchart in online supplementary fig. 1 (for all online suppl. material, see www. karger.com/doi/10.1159/000448683). In the euthyroid subjects, median TSH was $1.49 \mu \mathrm{IU} / \mathrm{ml}(\mathrm{IQR}=1.04-2.17$; range 0.41-4.00); in the SCH group, TSH was $5.00 \mu \mathrm{IU} /$ $\mathrm{ml}(\mathrm{IQR}=4.41-6.18$; range 4.01-141), and in the total group, it was $1.55 \mu \mathrm{IU} / \mathrm{ml}$ (IQR $=1.07-2.34$; range 0.41 141), $\mathrm{p}<0.0001$ (Mann-Whitney U test).

Table 1 shows the results by quintiles of TSH. Cutoffs for quintiles were as follows: $0.41-0.98 \mu \mathrm{IU} / \mathrm{ml}$ (first), $0.99-1.34 \mu \mathrm{IU} / \mathrm{ml}$ (second), $1.35-1.79 \mu \mathrm{IU} / \mathrm{ml}$ (third), $1.80-2.58 \mu \mathrm{IU} / \mathrm{ml}$ (fourth), and 2.59-141 $\mu \mathrm{IU} / \mathrm{ml}$ (fifth). The fifth quintile included 1,768 euthyroid individuals and all 695 subjects with SCH. Age, BMI, and frequency of women, whites, never smokers, obesity, and CKD increased according to ascending quintiles.

Table 2 shows the logistic regression models. Analysis by quintiles in the total sample showed that the fifth quintile of TSH was associated with higher hs-CRP using the first as reference $(\mathrm{OR}=1.20,95 \% \mathrm{CI}=1.07-1.36, \mathrm{p}=$ 0.003 ) in a model adjusted for sociodemographic characteristics and cardiovascular risk factors (model 2). However, the significance disappeared in the fifth quintile in comparison with the first after additional adjustment for insulin resistance and BMI: OR $=1.11$ (95\% CI $=0.98$ 1.26 ), $\mathrm{p}=0.102$ (model 3 ). Restricting the analysis to the euthyroid sample did not alter the results.

Table 3 shows the linear regression models, with results consistent with the logistic models. The model adjusted for sociodemographic characteristics and cardiovascular risk factors was significant $(\beta=0.057, p=0.001)$, but further adjustment for insulin resistance and BMI $(\beta=0.024, p=0.145)$ resulted in a lack of significance. Restricting the analysis to participants without diabetes, obesity, and insulin resistance did not change the results in logistic or linear models. We also analyzed the OR of a high hs-CRP level in participants with SCH as a categorical variable using euthyroid participants as the reference. Results were negative even in the crude logistic model $(\mathrm{OR}=1.11,95 \% \mathrm{CI}=0.95-1.29), \mathrm{p}=0.205$ (data not shown).

\section{Discussion}

Although we found an association in the crude logistic models and models adjusted for age, sex, and race, this association lost significance after adjustment for insulin resistance and BMI. The association remained significant for the fourth quintile in the logistic models; in the linear regression models, these factors lost significance after further adjustment for insulin resistance and BMI.

Data about the association between hs-CRP and thyroid function are not very consistent. Two cross-sectional analyses with a design similar to this study found conflicting results $[20,21]$. First, a cross-sectional analysis of a cohort of 2,494 participants recruited in Taiwan from 2006 to 2008 showed an association between SCH (TSH $>5.6 \mu \mathrm{IU} / \mathrm{ml}$ ) and elevated hs-CRP, defined as above the fourth quartile $(>24.67 \mathrm{nmol} / \mathrm{l})$, i.e. results consistent with ours [20]. In contrast with our population, they included a predominance of men (56\%), with a lower mean age (38 years). However, the multivariate linear model was adjusted for triglycerides, HDL cholesterol, smoking, and systolic BP, but not for BMI, insulin resistance, or CKD.

Using data from the NHANES in the United States, a cross-sectional analysis of 1,551 euthyroid subjects and 57 with SCH did not find any association between $\ln$ (hsCRP $)$ and SCH $(\beta=-0.017, p=0.941)$. The sample in this study had a slight predominance of men (51\%) and whites (52\%), and was older ( $\geq 40$ years of age). Multivariate linear adjustment was done for age, gender, race, use of cholesterol-lowering medication, and a composite of diabetes and prevalence of cardiovascular disease, hypertension, smoking, and obesity [21].

Similar to the NHANES data, other studies with different designs were not able to show a consistent association between $\mathrm{SCH}$ and increased hs-CRP. One Swiss double-blind placebo-controlled clinical trial showed that hs-CRP values increased progressively with thyroid failure in 63 subjects with $\mathrm{SCH}(\mathrm{p}=0.022)$, and particularly in 61 subjects with overt hypothyroidism ( $\mathrm{p}=$ 0.016 ), in comparison to 40 euthyroid matched controls. However, levothyroxine therapy over 48 weeks did not result in decreased hs-CRP in 31 subjects with SCH compared to 32 subjects with $\mathrm{SCH}$ randomized to the placebo group [33]. Consistent with this clinical trial, one retrospective South Korean study that followed individuals with $\mathrm{SCH}$ who were treated or not with levothyroxine did not find decreased serum hs-CRP levels in either group [34].

Another large South Korean study found no association between SCH and hs-CRP. One cross-sectional study with 66,620 subjects, predominantly men $(n=43,588)$, did not find differences in mean hs-CRP levels among patients with SCH (defined as TSH $>5.0 \mathrm{mIU} / \mathrm{l}$ and nor$\mathrm{mal}_{\mathrm{fT}}$ ) in comparison to euthyroid subjects after adjustment for age and sex [35]. Similarly, another smaller 
South Korean cross-sectional analysis examining data from outpatient checkups $(4,410$ euthyroid, $438 \mathrm{SCH}$, and 66 subjects with hyperthyroidism) [36] failed to demonstrate any association.

Our cross-sectional analysis did not detect an association between TSH and hs-CRP. Despite conflicting evidence about the relationship between thyroid function and CRP from cross-sectional analyses, some of them with large samples, other large observational studies have shown a strong relationship between overweight, obesity, abdominal obesity, metabolic syndrome, and increased hs-CRP in several populations [19, 37, 38]. Furthermore, other studies have proven that weight loss results in decreased hs-CRP levels in a dose-response relationship [19].

Similarly, Aronson et al. [38] found obesity to be the major determinant of elevated CRP in patients with the metabolic syndrome, while other large observational studies have also shown the association between insulin resistance and increased hs-CRP, suggesting cytokines originating from adipose tissue may play a role [39]. Instead of hs-CRP and thyroid function, the association between $\mathrm{SCH}$, insulin resistance, and the metabolic syndrome has been clearly shown in other large observational studies [10,40], including one using data from the ELSA-Brasil [10]. By contrast, little has been published about the direct inflammatory effect of SCH and its relation to the cardiovascular risk $[20,21]$. Two different studies presented conflicting results. One crosssectional study has reported that the cardiovascular risk in $\mathrm{SCH}$ patients is mediated by inflammatory pathways suggesting a dose-response effect [20]. However, crosssectional data from the NHANES reported that $\mathrm{SCH}$ was not associated with cardiac inflammation [21]. Our findings suggest that high TSH levels are related to hsCRP through its effects on fat depots and insulin resistance rather than a direct effect on this inflammatory marker.

\section{Study Limitations}

Although our results did not demonstrate a clear association between $\mathrm{SCH}$ and hs-CRP in an apparently healthy Brazilian adult population, it must be read within the context of the study design. This is a cross-sectional analysis which allows us to study associations but not causality. However, our results highlight the impact of adiposity and insulin resistance on hs-CRP as corroborated by evidence from large observational studies. Our study has also some strengths. Analysis by quintiles permitted us to draw conclusions about the impact of adiposity and insulin resistance on hs-CRP according to different levels of TSH in an apparently healthy population, especially in higher quintiles of TSH.

In conclusion, we did not find an association between increasing thyrotropin levels and higher hs-CRP levels when adjusted for cardiovascular risk factors, BMI, and insulin resistance, which was consistent with previous studies that suggested a potential role for cytokines originating from adipose tissue and systemic inflammation related to atherosclerosis and cardiovascular risks. We conclude that obesity and insulin resistance are potential mechanisms and very important confounders that mediate the effect of thyroid function on systemic inflammation in our population.

\section{Acknowledgments}

The ELSA-Brasil study was supported by the Brazilian Ministry of Health (Science and Technology Department) and the Brazilian Ministry of Science and Technology (Estudos e Projetos and CNPq National Research Council) (grants 01060010.00RS, 01060212.00BA, 01060300.00ES, 01060278.00MG, 01 060115.00 SP, 0106 0071.00RJ).

\section{Disclosure Statement}

No competing financial interests exist.

\section{References}

1 Tunbridge WM, Evered DC, Hall R, et al: The spectrum of thyroid disease in a community: the Whickham survey. Clin Endocrinol (Oxf) 1977;7:481-493.

2 Iervasi G, Molinaro S, Landi P, et al: Association between increased mortality and mild thyroid dysfunction in cardiac patients. Arch Intern Med 2007;167:1526-1532.
3 Walsh JP, Bremner AP, Bulsara MK, et al: Subclinical thyroid dysfunction as a risk factor for cardiovascular disease. Arch Intern Med 2005;165:2467-2472.

4 Cappola AR, Fried LP, Arnold AM, et al: Thyroid status, cardiovascular risk, and mortality in older adults. JAMA 2006;295:1033-1041.
5 Rodondi N, Newman AB, Vittinghoff E, et al: Subclinical hypothyroidism and the risk of heart failure, other cardiovascular events, and death. Arch Intern Med 2005; 165:2460-2466.

6 Rodondi N, den Elzen WP, Bauer DC, et al: Subclinical hypothyroidism and the risk of coronary heart disease and mortality. JAMA 2010;304:1365-1374. 
7 Liu D, Jiang F, Shan Z, et al: A cross-sectional survey of relationship between serum TSH level and blood pressure. J Hum Hypertens 2010;24:134-138.

8 Janssen IM, Homan J, Schijns W, et al: Subclinical hypothyroidism and its relation to obesity in patients before and after Roux-enY gastric bypass. Surg Obes Relat Dis 2015;11: 1257-1263.

-9 O'Brien T, Dinneen SF, O'Brien PC, et al: Hyperlipidemia in patients with primary and secondary hypothyroidism. Mayo Clin Proc 1993;68:860-866.

10 Benseñor IM, Goulart AC, Molina Mdel C, et al: Thyrotropin levels, insulin resistance, and metabolic syndrome: a cross-sectional analysis in the Brazilian Longitudinal Study of Adult Health (ELSA-Brasil). Metab Syndr Relat Disord 2015;13:362-369.

$\checkmark 11$ Hak AE, Pols HA, Visser TJ, et al: Subclinical hypothyroidism is an independent risk factor for atherosclerosis and myocardial infarction in elderly women: the Rotterdam Study. Ann Intern Med 2000;132:270-278.

12 Gao N, Zhang W, Zhang YZ, et al: Carotid intima-media thickness in patients with subclinical hypothyroidism: a meta-analysis. Atherosclerosis 2013;227:18-25.

13 Calabró P, Willerson JT, Yeh ET: Inflammatory cytokines stimulated C-reactive protein production by human coronary artery smooth muscle cells. Circulation 2003;108:19301932.

14 Ridker PM, Cook N: Clinical usefulness of very high and very low levels of C-reactive protein across the full range of Framingham risk scores. Circulation 2004;109:1955-1959.

-15 Ridker PM, Rifai N, Rose L, Buring JE, Cook NR: Comparison of C-reactive protein and low-density lipoprotein cholesterol levels in the prediction of first cardiovascular events. N Engl J Med 2002;347:1557-1565.

16 Cushman M, Arnold AM, Psaty BM, et al: Creactive protein and the 10 -year incidence of coronary heart disease in older men and women: the Cardiovascular Health Study. Circulation 2005;112:25-31.

17 Park R, Detrano R, Xiang M, et al: Combined use of computed tomography coronary calcium scores and C-reactive protein levels in predicting cardiovascular events in nondiabetic individuals. Circulation 2002;106:20732077.
18 Ridker PM, Danielson E, Fonseca FA, et al: Rosuvastatin to prevent vascular events in men and women with elevated C-reactive protein. N Engl J Med 2008;359:2195-2207.

19 Nicklas BJ, You T, Pahor M: Behavioural treatments for chronic systemic inflammation: effects of dietary weight loss and exercise training. CMAJ 2005;172:1199-1209.

20 Yu YT, Ho CT, Hsu HS, et al: Subclinical hypothyroidism is associated with elevated high-sensitive C-reactive protein among adult Taiwanese. Endocrine 2013;44:716722.

21 Hueston WJ, King DE, Geesey ME: Serum biomarkers for cardiovascular inflammation in subclinical hypothyroidism. Clin Endocrinol (Oxf) 2005;63:582-587.

22 Aquino EM, Barreto SM, Bensenor IM, et al: Brazilian Longitudinal Study of Adult Health (ELSA-Brasil): objectives and design. Am J Epidemiol 2012;175:315-324.

23 Bensenor IM, Griep RH, Pinto KA, et al: Routines of organization of clinical tests and in terviews in the ELSA-Brasil investigation center (in Portuguese). Rev Saude Publica 2013; 47(suppl 2):37-47.

24 Aquino EM, Araujo MJ, Almeida Mda C, et al: Participants recruitment in ELSA-Brasil (Brazilian Longitudinal Study for Adult Health) (in Portuguese). Rev Saude Publica 2013;47(suppl 2):10-18.

25 Hollowell JG, Staehling NW, Flanders WD, et al: Serum TSH, $\mathrm{T}_{4}$, and thyroid antibodies in the United States population (1988 to 1994): National Health and Nutrition Examination Survey (NHANES III). J Clin Endocrinol Metab 2002;87:489-499.

26 Surks MI, Ortiz E, Daniels GH, et al: Subclinical thyroid disease: scientific review and guidelines for diagnosis and management. JAMA 2004;291:228-238.

27 Singer P: Primary hypothyroidism due to other causes; in Braverman LE, Utiger RD (eds): Werner and Ingbar's The Thyroid: A Fundamental and Clinical Text, ed 9. Philadelphia, Lippincott-Williams \& Wilkins, 2005, pp 523-692.

28 Barbesino G: Misdiagnosis of Graves' disease with apparent severe hyperthyroidism in a patient taking biotin megadoses. Thyroid 2016;26:860-863.

29 Levey AS, Stevens LA, Schmid CH, et al: A new equation to estimate glomerular filtration rate. Ann Intern Med 2009;150:604-612.

- 30 Barreto SM, Ladeira RM, Duncan BB, et al: Chronic kidney disease among adult participants of the ELSA-Brasil cohort: association with race and socioeconomic position. J Epidemiol Community Health 2016;70:380-389.
31 Lorenzo C, Williams K, Hunt KJ, et al: The National Cholesterol Education Program Adult Treatment Panel III, International Diabetes Federation, and World Health Organization definitions of the metabolic syndrome as predictors of incident cardiovascular disease and diabetes. Diabetes Care 2007;30:813.

32 Wilson PW, D'Agostino RB, Levy D, et al: Prediction of coronary heart disease using risk factor categories. Circulation 1998;97: 1837-1847.

33 Christ-Crain M, Meier C, Guglielmetti M, et al: Elevated C-reactive protein and homocysteine values: cardiovascular risk factors in hypothyroidism? A cross-sectional and a double-blind, placebo-controlled trial. Atherosclerosis 2003; 166:379-386.

34 Lee MW, Shin DY, Kim KJ, et al: The biochemical prognostic factors of subclinical hypothyroidism. Endocrinol Metab (Seoul) 2014;29:154-162.

35 Jung $\mathrm{CH}$, Sung KC, Shin HS, et al: Thyroid dysfunction and their relation to cardiovascular risk factors such as lipid profile, hsCRP, and waist hip ratio in Korea. Korean J Intern Med 2003;18:146-153.

36 Nah EH, Lee JG: The relationship between thyroid function and the risk factors of cardiovascular disease at female medical checkups (in Korean). Korean J Lab Med 2009;29: 286-292.

37 Visser M, Bouter LM, McQuillan GM, et al: Elevated C-reactive protein levels in overweight and obese adults. JAMA 1999;282: 2131-2135.

-38 Aronson D, Bartha P, Zinder O, et al: Obesity is the major determinant of elevated C-reactive protein in subjects with the metabolic syndrome. Int J Obes Relat Metab Disord 2004;28:674-679.

39 Yudkin JS, Stehouwer CD, Emeis JJ, et al: Creactive protein in healthy subjects: associations with obesity, insulin resistance, and endothelial dysfunction: a potential role for $\mathrm{cy}$ tokines originating from adipose tissue? Arterioscler Thromb Vasc Biol 1999;19:972978.

40 Garduño-Garcia Jde J, Alvirde-Garcia U, López-Carrasco G, et al: TSH and free thyroxine concentrations are associated with differing metabolic markers in euthyroid subjects. Eur J Endocrinol 2010;163:273-278. 